motivate them further by inviting them to come back in a couple of weeks to report on progress.

A final thought. If we are prepared to tackle the 'no sex' issue head on and spend just a little time with patients exploring the issues, then we're not just supporting them to get the help they need. We're also giving them the message that they deserve that help, that their sexuality matters, and that they don't simply have to accept their current 'no sex' status if they want to take action and change it. And actually, in 'no sex' situations, that message - above and beyond any other intervention we can offer - could just be the most useful thing of all.

References

1 Mercer CH, Fenton KA, Johnson AM, Copas AJ, Macdowall W, Erens B, et al. Who reports sexual function problems? Empirical evidence from Britain's 2000 National Survey of Sexual Attitudes and Lifestyles. Sex Transm Infect 2005; 81: 394-399.

2 Quilliam S. Women on Sex. London, UK: Smith Gryphon, 1994.

Editor's Note

Susan’s latest book is Body Language (£12.99, Carlton Books Limited).

\title{
PBC: practice-based commissioning or privatisation becoming commonplace?
}

Jenny Talia

\section{Reform and restructuring}

Here we go again, more market reform of the National Health Service (NHS). As if we haven't had enough of the expensive bureaucracy and inequities of general practitioner (GP) fund-holding in the 1990s. And this time they are serious about putting GPs in the driving seat to commission health care services for their community; apparently, this is to enable frontline clinicians to engage in the process of commissioning.

Call me stupid but I thought the whole point of professional executive committees (PEC) in primary care trusts (PCTs) was to 'engage the frontline' and 'shift the balance of power'. If the Government really wanted to strengthen this engagement then it is the role and function of the PEC in the PCT that needs to be strengthened.

GPs might be very good at arguing for their own and their patients' interests, but the experience of fund-holding makes me fear my peers might not necessarily see the 'big picture' to manage the health economy. This time round, you would think a framework would be set for priority setting and resource allocation. Apparently not. All the guidance on PBC from the Department of Health speak of vague aspirations without stipulating any rules or regulations to ensure the process adheres to a framework that addresses the nation's health priorities. Even the primary care organisations - restructured and very downsized by then - would only have control at arm's length; just like the 'high trust and light touch' approach with the Quality and Outcomes Framework (QOF).

The input from a public health practitioner would be paramount to ensure the commissioning process considers the dimensions of equity, cost effectiveness and patient choice. Otherwise services that have public health functions, like most of sexual and reproductive health services, would be seen as less deserving compared with others that offer quick fixes such as operations and therapies. Actually, the contracting and commissioning would be a very small part of PBC; what matters more is the priority setting for resource allocation and the subsequent performance management and outcomes monitoring of contracted services.

J Fam Plann Reprod Health Care 2006; 32(1): 51

Pastures Green, UK

Jenny Talia, MRCGP, MSc, General Practitioner

\section{The truth and the economics}

But here is the real but sinister agenda: this is privatisation of the NHS dressed up in the mantras of 'promoting clinical engagement' and 'patient choice'. Of course, there is nothing wrong with trying to improve efficiency, standards, access and choice; but is creating competition in a health care market the solution?

From a health economist's perspective, the NHS is a monopoly. A technically or economically inefficient monopolist cannot be driven out of business; without competition, the monopolist has no incentive to improve efficiency or improve quality. Introducing competition might encourage firms to improve their products; in this case, better and more responsive health care services. However, a firm doesn't want to reap the same profits as its competitors, so it operates in ingenious ways to get ahead, and in doing so eventually becomes a monopolist. This is the question they are afraid to ask the public: would you prefer a monopolist that is motivated by altruism or one that is driven by profit?

The American nightmare, not a dream

It is becoming clear that Iraq is not the only casualty of the Bush-Blair collaboration: the NHS is under threat. After many trips to the USA, our Prime Minister is brainwashed into thinking the American health care system is what we need. If the Prime Minister really likes it so much, he should stay there. What does the USA have to teach us? The American health care system has the worst population coverage where the poor, black and unemployed are most disadvantaged; it has the highest per capita spending on health and yet no better health outcome than the UK; and its teenage pregnancy rate is the highest in the Western world. Even the French, despite their claim to have the "best health care system in the world', are looking across the Channel to see how we manage to contain health care costs.

$\mathrm{PBC}$ and increasing competition are not the solutions to cost effectiveness, choice and quality in a publicly funded health system. The Prime Minister has learnt, rather belatedly, that there is potential for distorted priorities in a popularist agenda such as the 48-hour access. After this reform, the winners would be politicians and shareholders of private companies and the real losers would be the consumers. If they get their way, you could walk into any GP surgery in the country and demand a speedy hernia or varicose vein operation from a choice list of ten hospitals; but try to get the rates of teenage conceptions and chlamydia down? Forget it. 